\title{
Association between vitamin D levels and arterial hypertension in women at very high cardiovascular risk
}

\author{
Bartosz Krzowski', Anna E. Platek ${ }^{1,2}$, Anna Rys', Karolina Semczuk', Marcin Kotkowski ${ }^{1,2}$,

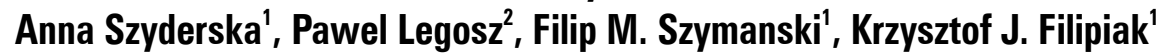 \\ ${ }^{1} 1^{\text {st }}$ Department of Cardiology, Medical University of Warsaw, Warsaw, Poland \\ ${ }^{2}$ Department of General and Experimental Pathology with Centre for Preclinical Research and Technology (CEPT), \\ Medical University of Warsaw, Warsaw, Poland \\ ${ }^{3}$ Department of Orthopaedics and Traumatology of the Musculoskeletal System, Medical University of Warsaw, Warsaw, Poland
}

\begin{abstract}
Background. Vitamin D is a compound of great importance in controlling the biological functions of the body in a variety of ways. Significance of vitamin $D$ in the pathogenesis and treatment of various diseases has been described repeatedly. One of the most discussed issues in the literature is the importance of vitamin D deficiency in the pathogenesis of hypertension. This relationship is particularly important in patients burdened with elevated cardiovascular risk, which undoubtedly represent patients with diagnosed disease of the cardiovascular system. The aim of the study was to determine the association between the occurrence of vitamin $\mathrm{D}$ deficiency and the prevalence of hypertension in premenopausal women at very high cardiovascular risk.

Materials and methods. The study included 49 women who had previously been diagnosed with cardiovascular disease. In all patients enrolled in the study serum concentrations of vitamin $D$ were measured and the patients were classified to have vitamin D deficiency or normal vitamin D level, based on the existing criteria. The patients were also tested for the occurrence of hypertension. Medical records of all patients were reviewed for early diagnosis of hypertension, and blood pressure measurements were performed on admission to the hospital before the surgery by a qualified physician, in a manner consistent with current guidelines

Results. The study population was aged $47.7 \pm 13.4$ years. The mean body mass index was $25.2 \mathrm{~kg} / \mathrm{m}^{2}$. Vitamin D deficiency was diagnosed in $25(51 \%)$ patients, and hypertension was diagnosed in 30 women (61.2\%). In patients with vitamin D deficiency hypertension occurred in $18(72 \%)$ women, while in the group without vitamin D deficiency hypertension was diagnosed in $50 \%$ of cases (12 women). The observed difference between the groups was statistically significant $(\mathrm{p}=0.049)$. There was no difference in the incidence of other cardiovascular risk factors between the groups, including the prevalence of dyslipidaemia or nicotine addiction.

Conclusion. Association of hypertension with the vitamin D deficiency has been repeatedly underlined in many scientific studies. In the present group of patients at very high cardiovascular risk, we confirmed the relationship of vitamin D deficiency with the occurrence of hypertension. Exact confirmation of this issue requires further, largescale research, but this study may suggest the importance of vitamin $\mathrm{D}$ supplementation in these patients.
\end{abstract}

key words: vitamin $\mathrm{D}$, hypertension, premenopausal women

Arterial Hypertens. 2016, vol. 20, no. 3, pages: 102-107

DOI: $10.5603 / A H .2016 .0015$

\footnotetext{
Address for correspondence: Filip M. Szymanski, MD, PhD

$1^{\text {st }}$ Department of Cardiology,

Medical University of Warsaw

1 A Banacha Street, 02-097 Warsaw, Poland

Tel.: (++48 22) 599-19-58; fax: (++48 22) 599-19-57

e-mail address: filip.szymanski@wum.edu.pl
}

VM Copyright (C) 2016 Via Medica, ISSN 2449-6170 


\section{Introduction}

Vitamin D is lipid soluble prohormone synthesised in the skin after exposure to sunlight. It can be also delivered with food. Vitamin $\mathrm{D}$ in its active form has lots of differentiated effects, which include influencing bone and muscle metabolism as well as control of other vital mechanisms. More and more findings from various areas of medicine are published, e.g. dermatological use of vitamin D - in patients with systemic lupus erythematosus [1], patients with melanoma [2], endocrinology - levels of vitamin D are connected with the risk of diabetes type 2 and obesity [3]. Moreover, sufficient level of vitamin D is important for proper embryo implantation, trophoblast invasion and angiogenesis during pregnancy [4]. Cardiovascular impact of this substance is debated. In the cardiovascular system vitamin D plays crucial role in renin-angiotensin-aldosterone system activation, which leads to the development of one of the most widespread diseases - arterial hypertension (HTN). HTN affects over 1 billion people worldwide and large portion of this group are women [5]. HTN is not only a widespread disease, it is also a risk factor for further cardiovascular consequences. Therefore, current study aims to describe whether vitamin D levels play important role in the development of hypertension in women with cardiovascular disease.

\section{Material and methods}

\section{Study population}

This was a prospective, observational cohort study performed in order to establish the prevalence of arterial hypertension in consecutive patients at very high cardiovascular risk screen in a tertiary University Hospital.

The study was conducted with respect to the Declaration of Helsinki and an approval form the Ethics Committee by the Medical University of Warsaw was obtained before the beginning of the study. Written, informed consent was obtained from every study participant prior to the study enrolment.

The study cohort consisted of premenopausal consecutive female patients whose "very-high CVD risk" status was established with respect to the current guidelines. Criteria for very high risk included: documented CVD, clinical or unequivocal on imaging (includes previous myocardial infarction, acute coronary syndrome, coronary revascularization and other arterial revascularization procedures, stroke and transient ischaemic attack, aortic aneurysm and peripheral artery disease); diabetes mellitus with target organ damage such as proteinuria or with a major risk factor such as smoking or marked hypercholesterolaemia or marked hypertension; severe chronic kidney disease; or a calculated SCORE $\geq 10 \%$. In all patients enrolled in the study, serum concentrations of vitamin $\mathrm{D}$ were measured and patients were classified to have or not have the vitamin D deficiency, based on the existing criteria.

Patients were recruited into the study between 2015 and 2016. The study population consisted only of patients in whom the medical records allowed valid assessment of blood pressure values and current medical treatment. Exclusion criteria were: age < 18 or $\geq 55$ years, myocardial infarction, stroke or decompensation of heart failure within the last six months and absence of written informed consent.

Data on demographics, lifestyle, comorbidity and cardiovascular risk factors were obtained. Demographic variables were analysed included age and sex. Comorbidities studied included presence or absence of heart failure, diabetes mellitus, stroke or TIA episodes, myocardial infarction episodes, peripheral artery disease, dyslipidaemia, coronary artery disease, important valvular defect, asthma, chronic obstructive pulmonary disease, $\mathrm{CABG}, \mathrm{PCI}$, cardiac pacemaker implanted. All patients were also screened for other classical and non-classical cardiovascular risk factors including diabetes mellitus, dyslipidaemia, or history of cardiovascular disease. Diagnosis of all factors was made based on eligible medical records, taking prescription drugs applicable for the respective disease (i.g. hypoglycaemic agents for diabetes), or as a de novo diagnosis according to the current diagnostic criteria.

\section{Screening for arterial hypertension}

All study participants were screened for HTN. Patients had their blood pressure measured on admission by a qualified physician. Diagnosis of arterial hypertension was made when office blood pressure was equal or exceeded the values of 140 for systolic blood pressure (SBP) and/or 90 for diastolic blood pressure (DBP). The number of required measurements, measurement techniques and settings were in accordance with the current guidelines for arterial hypertension diagnosis and management of the European Society of Cardiology and European Society of Hypertension. The diagnosis was also made where there were eligible medical records available on previous diagnosis of arterial hypertension or taking prescription hypotensive agents. 


\section{Laboratory testing}

Blood samples were collected after hospitalization before surgery, after a 20-minute rest following 12 hours of fasting. Due to long half-life, serum 25 hydroxy $(\mathrm{OH})$ vitamin $\mathrm{D}$ was preferred instead of 1,25 dihydroxy vitamin $\mathrm{D}$. As serum $25(\mathrm{OH})$ vitamin $\mathrm{D}$ levels show a seasonal variability, in order to obtain standard measurements, only patients who were operated in fall and winter seasons were examined. Serum $25(\mathrm{OH})$ D levels were measured by direct chemiluminescence immunoassay (Elecsys; Roche Diagnostics, Mannheim, Germany) method. Vitamin D deficiency was defined as levels $\leq 20 \mathrm{ng} / \mathrm{mL}$. Intra- and inter-assay coefficients of variation (CVs) were below $4.5 \%$ and $7.6 \%$, respectively.

\section{Statistical analysis}

Statistical analysis was performed using the SAS software version 8.02 (SAS Institute, Inc., Cary, NC, USA). Continuous data are presented as mean \pm standard deviation (SD) and were compared using the Mann-Whitney test or Student's t-test. Categorical variables were compared using either the $\chi^{2}$ or Fisher's exact tests. A p value of less than 0.05 was considered statistically significant, whereas the confidence intervals (CI) were $95 \%$.

\section{Results}

The study population was aged $47.7 \pm 134$ years. The mean body mass index was $25.2 \mathrm{~kg} / \mathrm{m}^{2}$. Vitamin D deficiency was diagnosed in $25(51 \%)$ patients. In contrast, hypertension was diagnosed in 30 women (61.2\%). The second most prevalent risk factor in this group of patients was dyslipidaemia $(44.9 \%$ of patients), with the mean LDL cholesterol level of $109.1 \pm 46.8 \mathrm{mg} / \mathrm{dL}$. In the current population, premenopausal, very high CVD-risk patients often suffered from overweight $(34.7 \%)$ and were current smokers (42.9\%) (Table I).

After dividing the patients according to the vitamin D levels, we observed following trends. In patients with vitamin $\mathrm{D}$ deficiency hypertension occurred in $18(72 \%)$ women, while in the group without deficiency hypertension was diagnosed in $50 \%$ of cases (12 women). The observed difference between the groups was statistically significant $(\mathrm{p}=$ 0.049 ). There was no difference in the incidence of other cardiovascular risk factors between the groups, including the prevalence of dyslipidaemia or nicotine addiction (Table II, Figure 1). Interestingly, we also found that in patients without vitamin D deficiency
Table I. Baseline characteristics of the study population

\begin{tabular}{|l|c|}
\hline Parameter $\mathbf{n}(\%)$ or mean \pm SD & Value \\
\hline Age (years) & $47.7 \pm 13.4$ \\
\hline Arterial hypertension & $30(61.2 \%)$ \\
\hline Dyslipidaemia & $22(44.9 \%)$ \\
\hline LDL-cholesterol level $[\mathrm{mg} / \mathrm{dL}]$ & $109.1 \pm 46.8$ \\
\hline Smoking & $21(42.9 \%)$ \\
\hline Overweight & $17(34.7 \%)$ \\
\hline BMl $\left[\mathrm{kg} / \mathrm{m}^{2}\right]$ & $25.2 \pm 5.9$ \\
\hline Vitamin D deficiency $[\leq 20 \mathrm{ng} / \mathrm{mL}]$ & $25(51.0 \%)$ \\
\hline Vitamin D level $[\mathrm{ng} / \mathrm{mL}]$ & $109.1 \pm 9.4$ \\
\hline
\end{tabular}

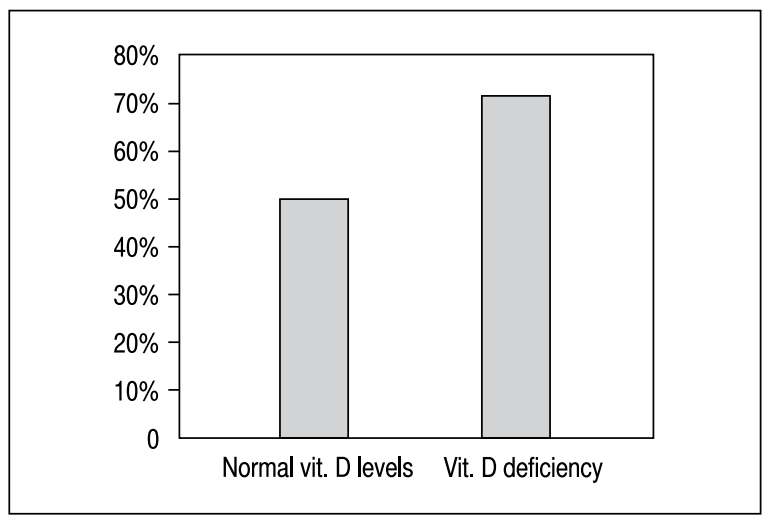

Figure 1. Prevalence of arterial hypertension according to the vitamin $D$ levels

Table II. Characteristics of the group with and without vitamin D deficiency

\begin{tabular}{|l|c|c|c|}
\hline Parameter $\mathbf{n}(\%)$ or mean $\mathbf{~ S D ~}$ & $\begin{array}{c}\text { Patients without vitamin D } \\
\text { deficiency }(\mathbf{n}=24)\end{array}$ & $\begin{array}{c}\text { Patients with vitamin D } \\
\text { deficiency }(\mathbf{n}=25)\end{array}$ & p value \\
\hline Arterial hypertension & $12(50.0 \%)$ & $18(72.0 \%)$ & 0.049 \\
\hline Dyslipidaemia & $7(29.2 \%)$ & $15(60.0 \%)$ & 0.03 \\
\hline LDL-cholesterol level [mg/dL] & $104.7 \pm 37.7$ & $113.0 \pm 54.1$ & 0.29 \\
\hline Smoking & $12(50.0 \%)$ & $9(36.0 \%)$ & 0.24 \\
\hline Overweight & $9(37.5 \%)$ & $8(32.0 \%)$ & 0.46 \\
\hline BMl $\left[\mathrm{kg} / \mathrm{m}^{2}\right]$ & $26.4 \pm 6.2$ & $24.3 \pm 5.7$ & 0.21 \\
\hline Vitamin D level $[\mathrm{ng} / \mathrm{mL}]$ & $28.1 \pm 7.0$ & $11.4 \pm 3.9$ & $<0.001$ \\
\hline
\end{tabular}


Table III. Characteristics of the group with and without arterial hypertension

\begin{tabular}{|l|c|c|c|}
\hline Parameter $\mathbf{n}(\%)$ or mean \pm SD & $\begin{array}{c}\text { Patients without arterial } \\
\text { hypertension }(\mathbf{n}=19)\end{array}$ & $\begin{array}{c}\text { Patients with arterial } \\
\text { hypertension }(\mathbf{n}=\mathbf{3 0})\end{array}$ & $\mathbf{p}$ value \\
\hline Dyslipidaemia & $9(47.4 \%)$ & $13(43.3 \%)$ & 0.51 \\
\hline LDL-cholesterol level $[\mathrm{mg} / \mathrm{dL}]$ & $103.9 \pm 34.7$ & $112.3 \pm 53.4$ & 0.94 \\
\hline Smoking & $9(47.4 \%)$ & $12(40.0 \%)$ & 0.42 \\
\hline Overweight & $8(42.1 \%)$ & $9(30.0 \%)$ & 0.29 \\
\hline BMI $\left[\mathrm{kg} / \mathrm{m}^{2}\right]$ & $25.9 \pm 6.1$ & $24.7 \pm 5.8$ & 0.13 \\
\hline Vitamin D deficiency $[\leq 20 \mathrm{ng} / \mathrm{mL}]$ & $12(63.2 \%)$ & $13(68.4 \%)$ & 0.049 \\
\hline Vitamin D level $[\mathrm{ng} / \mathrm{mL}]$ & $13.1 \pm 4.2$ & $19.1 \pm 10.9$ & 0.69 \\
\hline
\end{tabular}

there was a lower prevalence of dyslipidaemia (29.2 vs. $60.0 \% ; \mathrm{p}=0.03$ ) (Figure 2).

Additional analysis comparing baseline characteristics of patients with and without diagnosed HTN was also performed (Table III), but no significant differences between the groups were found.

\section{Discussion}

HTN is one of the most important risk factors for cardiovascular disease (CVD) [6]. It is estimated, that by 2025 the number of people with HTN will grow up to 1.56 billion [7]. This is one of the reasons why there is such desire to understand this illness as much in detail as possible. One of the new factors connected with HTN is vitamin D serum levels.

More people are being diagnosed with HTN during winter, and living in higher latitudes [8]. This leads to hypothesis that vitamin $\mathrm{D}$ deficiency may be connected with HTN. This concept has been tested in lots of clinical trials. However, the outcomes are inconsistent. Some trials showed connection between $25(\mathrm{OH}) \mathrm{D}$ serum level and blood pressure (BP), and some didn't. Moreover, other trials showed that vitamin D levels are associated with development and course of not only HTN but also other CVDs including coronary heart disease and heart failure [9-12].

One of the first clinical trials that were supposed to find connection between vitamin D level and HTN was made in 1988. It was a placebo-controlled trial which evaluated the effect of vitamin $D$ analogue on BP. All the patients were hypertensive and had impaired glucose tolerance (mean age 62, $\mathrm{n}=26$ ). Significant reduction in both systolic blood pressure (SBP) and diastolic blood pressure (DBP) was found from $171 / 95$ to $150 / 88 \mathrm{~mm} \mathrm{Hg}$ [13]. Another early trial was performed by Krause et al. who assessed patients with untreated mild HTN and vitamin D

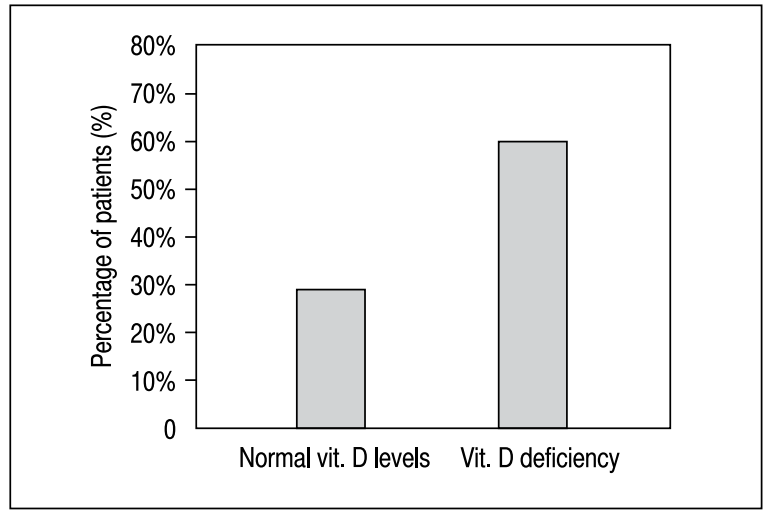

Figure 2. Prevalence of dyslipidaemia according to the vitamin D levels

deficiency, who were later treated with UVB radiation. The study showed increase in $25(\mathrm{OH}) \mathrm{D}$ level associated with BP reduction [14]. Both mentioned studies raised huge interest among researchers, which lead to lots of trials performed. As the effect, we have many meta-analyses now. One of them included 283537 non-overlapping participants and 55816 patients with HTN. Authors suggested, that every $10 \mathrm{ng} / \mathrm{mL}$ increase in blood vitamin D level reduces risk of HTN by $12 \%$ [15]. Another meta-analysis of four controlled trials made by Wu et al. showed significant reduction in SBP $(-2,44 \mathrm{~mm} \mathrm{Hg})$ without reduction of DBP [16] in hypertensive population. Another randomized, double-blind, placebo-controlled trial in Denmark was performed during winter. The authors checked the effect of $3000 \mathrm{IU} /$ day vitamin D supplementation on BP in hypertensive patients. The biggest decrease in $\mathrm{BP}$ was observed in patients with $25(\mathrm{OH}) \mathrm{D}$ deficiency at the beginning of the trial [17]. This finding suggests that high-dose vitamin D supplementation is more effective in hypertensive population, and that vitamin D deficiency may be connected with HTN.

Unfortunately, not every trial can lead to a strong conclusion. A placebo-controlled, randomized trial 
was performed to establish if vitamin D supplementation (2000 IU/day) reduces BP during 6 months. The study included 126 patients, all of whom received nifedipine. Reduction of $\mathrm{BP}$ and increase in $25(\mathrm{OH}) \mathrm{D}$ blood level was registered. The biggest reduction of BP was noticed in patients who had vitamin $\mathrm{D}$ deficiency, which suggests that vitamin $\mathrm{D}$ supplementation plays bigger role in patients with hypertension and vitamin D deficiency [18]. Another trial confirming above conclusion was run in Iran, where 8-week, randomized placebo-controlled trial took place. After 8 weeks of vitamin D supplementation its level raised and BP lowered significantly in hypertensive population [19]. The weakness of both mentioned trials was that all the patients were treated with antihypertensive drug, which might have covered $25(\mathrm{OH}) \mathrm{D}$ effect.

However there were also trials that showed no effect of vitamin D supplementation on BP. One of them was performed by Arora $e t$ al. The authors enrolled population of 534 patients aged between 18 and 50 with vitamin D deficiency, but only $28 \%$ of them were hypertensive [20]. The strength of this trial was that the patients didn't take antihypertensive drug, but on the other hand, the patients were young and mostly normotensive. Six-month supplementation of vitamin $\mathrm{D}$ failed to reduce BP. That leads to conclusion that vitamin $\mathrm{D}$ supplementation plays bigger role in patients with HTN.

The trial that focused on women only, just like ours, was the Woman's Health Initiative. The difference between these trials was the patients' age: our patients were younger. The authors enrolled population of 36282 postmenopausal woman. Supplementation of vitamin D and calcium didn't result in decreased number of hypertensive patients [21]. The weakness of this study was that patients received very low vitamin $\mathrm{D}$ dose (400 IU/day), which could result in increasing $25(\mathrm{OH}) \mathrm{D}$ blood level only by $2 \mathrm{ng} / \mathrm{mL}$. The dose for vitamin $\mathrm{D}$ supplementation remains debated, with recommendations varying by country, usually oscillating around 1000 IU/day [22]. The most similar trial to ours, with population of 1484 non-obese, young women (median age was 43) without hypertension suggested that lower plasma $25(\mathrm{OH}) \mathrm{D}$ levels are independently associated with a higher risk of incident hypertension [23]. Those results match with our outcome.

The inverse association between $25(\mathrm{OH}) \mathrm{D}$ plasma level and HTN may be explained by the fact that vitamin D is an excellent marker of good health, being connected with healthy lifestyle, young age and normal body weight [24]. Others claim that vitamin $\mathrm{D}$ inhibits renin expression $[25,26]$. Additional pathway of vitamin D lowering BP may be connected with parathyroid hormone (PTH). PTH is connected with increased BP, myocardial hypertrophy and ventricular arrhythmias [23]. Secretion of PTH is inhibited by vitamin D [27]. What is more, expression of $1 \alpha$-hydroxylase can be downregulated by PTH [27]. This leads to the conclusion that there is a feedback loop between vitamin $\mathrm{D}$ metabolism and PTH. Of course, to discuss all the additional findings and suggestions of the pathogenesis another article would be needed.

\section{Conclusion}

Connection between vitamin D deficiency and hypertension has been raised in many trials resulting in mixed outcomes, with advantage of the ones suggesting clear connection of HTN with $25(\mathrm{OH})$ $\mathrm{D}$ serum level. Additionally, the association between vitamin D deficiency and HTN is still unknown. That is why discussed issue requires more and much bigger clinical trials to understand it better. However, our trial suggests how important supplementation of vitamin $\mathrm{D}$ may be in the group of high cardiovascular risk woman.

\section{References}

1. Szymański F.M., Bomba-Opoń D.A., Łegoosz P. et al. Miejsce witaminy D w codziennej praktyce klinicznej — interdyscyplinarne stanowisko ekspertów. Forum Medycyny Rodzinnej 2015; 9: 391-402.

2. Rutkowski P., Wysocki P.J., Nowecki Z.I. i wsp. Czerniaki skóry zasady postępowania diagnostyczno-terapeutycznego w 2013 roku. Przegl. Dermatol. 2013; 100: 1-15.

3. Alvarez J.A., Ashraf A. Role of Vitamin D in insulin secretion and insulin sensitivity for glucose homeostasis. Int. J. Endocrinol. 2010; 35: 385-389.

4. Shin J.S., Choi M.Y., Longtine M.S., Nelson D.M. Vitamin D effects on pregnancy and the placenta. Placenta 2010;31: 1027-1034.

5. Joffres M., Falaschetti E., Gillespie C. et al. Hypertension prevalence, awareness, treatment and control in national surveys from England, the USA and Canada, and correlation with stroke and ischaemic heart disease mortality: a cross-sectional study. BMJ Open 2013; 3: $\mathrm{e} 003423$

6. Chobanian A.V. Shattuck Lecture. The hypertension paradox more uncontrolled disease despite improved therapy. N. Engl. J. Med. 2009; 361: 878-87.

7. Cifkova R., Fodor G., Wohlfahrt P. Changes in Hypertension Prevalence, Awareness, Treatment, and Control in High-, Middle-, and Low-Income Countries: An Update. Curr. Hypertens. Rep. 2016; 18: 62.

8. Rostand S.G. Ultraviolet light may contribute to geographic and racial blood pressure differences. Hypertension 1997; 30: 150-156.

9. Tokarz A., Kusnierz-Cabala B., Kuźniewski M., Gacoń J., Mazur-Laskowska M., Stępień E.Ł. Seasonal effect of vitamin D deficiency in patients with acute myocardial infarction. Kardiol. Pol. 2016 Jan 18. doi: 10.5603/KP.a2016.0002. [Epub ahead of print]. 
10. Oz F., Cizgici A.Y., Topuz M. et al. Vitamin D insufficiency is associated with coronary artery tortuosity. Kardiol Pol. 2016 Jul 8. doi: 10.5603/KP.a2016.0110. [Epub ahead of print].

11. Cerit L., Duygu H., Gulsen K. et al. Relation between vitamin B12 and SYNTAX Score. Kardiol Pol. 2016 Jul 8. doi: 10.5603/ KP.a2016.0108.

12. Makarewicz-Wujec M., Kozłowska-Wojciechowska M., Sygnowska E., Waśkiewicz A. Does heart failure determine the nutrition of patients? Kardiol. Pol. 2014; 72: 56-63.

13. Lind L., Lithell H., Skarfors E., Wide L., Ljunghall S. Reduction of blood pressure by treatment with alphacalcidol. A double-blind, placebo-controlled study in subjects with impaired glucose tolerance. Acta Med. Scand. 1988; 223: 211-217.

14. Krause R., Buhring M., Hopfenmuller W., Holick M.F., Sharma A.M. Ultraviolet B and blood pressure. Lancet 1998; 352: 709-710.

15. Chen S., Sun Y., Agrawal D.K. Vitamin D deficiency and essential hypertension. J. Am. Soc. Hypertens. 2015; 9: 885-901.

16. Wu S.H., Ho S.C., Zhong L. Effects of vitamin D supplementationon blood pressure. South Med. J. 2010; 103: 729-737.

17. Larsen T., Mose F.H., Bech J.N., Hansen A.B., Pedersen E.B. Effect of cholecalciferol supplementation during winter months in patients with hypertension: a randomized, placebo-controlled trial. Am. J. Hypertens. 2012; 25: 1215-1222.

18. Chen W.R., Liu Z.Y., Shi Y. et al. Vitamin D and nifedipine in the treatment of Chinese patients with grades I-II essential hypertension: a randomized placebo-controlled trial. Atherosclerosis 2014; 235: 102-109.
19. Mozaffari-Khosravi H., Loloei S., Mirjalili M.R., Barzegar K. The effect of vitamin $\mathrm{D}$ supplementation on blood pressure in patients with elevated blood pressure and vitamin D deficiency: a randomized, doubleblind, placebo-controlled trial. Blood Press. Monit. 2015; 20: 83-91.

20. Arora P., Song Y., Dusek J. et al. Vitamin D therapy in individuals with pre-hypertension or hypertension. The DAYLIGHT Trial. Circulation 2015; 131: 254-262.

21. Hsia J., Heiss G., Ren H. et al.; Women's Health Initiative Investigators. Calcium/vitamin D supplementation and cardiovascular events. Circulation 2007; 115: 846-854.

22. Spiro A., Buttriss J.L. Vitamin D: an overview of vitamin D status and intake in Europe. Nutr. Bull. 2014; 39: 322-350.

23. Forman J.P., Curhan G.C., Taylor E.N. Plasma 25-hydroxyvitamin $\mathrm{D}$ levels and risk of incident hypertension among young women. Hypertension 2008; 52: 828-832.

24. Prentice A., Goldberg G.R., Schoenmakers I. Vitamin D across the lifecycle: physiology and biomarkers. Am. J. Clin. Nutr. 2008; 88: 500S-506S.

25. Li Y.C., Kong J., Wei M., Chen Z.F., Liu S.Q., Cao L.P. 1,25-Dihydroxyvitamin $\mathrm{D}(3)$ is a negative endocrine regulator of the renin-angiotensin system. J. Clin. Invest. 2002; 110: 229-238.

26. Li Y.C., Kong J., Wei M., Chen Z.F., Liu S.Q., Cao L.P. 1,25-Dihydroxyvitamin $\mathrm{D}(3)$ is a negative endocrine regulator of the renin-angiotensin system. J. Clin. Invest. 2002; 110: 229-238.

27. Somjen D., Weisman Y., Kohen F. et al. 25-hydroxyvitamin D3-1 alpha-hydroxylase is expressed in human vascular smooth muscle cells and is upregulated by parathyroid hormone and estrogenic compounds, Circulation 2005; 111: 1666-1671. 